\title{
Simular el Territorio
}

\author{
SIMULATE THE TERRITORY
}

\section{SIMULAR O TERRITÓRIO}

Ignacio Rodríguez Srabonián *1

sujetorama@gmail.com

\section{Resumen}

El territorio es una figura que se puede pensar desde el simulacro. Este último representa una posible amenaza de interpretación en tanto que no mantiene distancia de su referente. Su imagen geográfica puede no diferenciarse del territorio o viceversa. Lo mismo sucede con la práctica fotográfica heredera de una tradición mimética donde su realismo ha producido efectos sociales aplicados a la publicidad, la ciencia o prácticas de espectacularización. Desde esta reflexión inicial, se observa Punta del Este como ejemplo de ciudad turística en disputa por el territorio y el espacio público. El desplazamiento de comunidades, la excepción a normativas de construcción, la competencia por espacios publicitarios, entre otros, son ejemplo de las tensiones que ocurren en este lugar. No obstante, no siempre son parte de lo visible o narrado. Desde esta observación, se propone la visita del proyecto artístico Bienvenidos como disparador para pensar dispositivos que enuncian desde un lugar extra-académico y pensar tensiones vinculadas al territorio y los espacios públicos. Bienvenidos es un proyecto que tiene como objetivo señalar y dar visibilidad a algunos procesos de segregación que presenta la ciudad en tanto territorio en tensión de intercambios públicos y privados. Utiliza estrategias como la puesta en escena y recursos creativos asociados a la publicidad y el mercado de bienes raíces. Se propone el proyecto artístico para pensar desde lo contemporáneo el territorio como una forma más de producción subjetiva relacionada a prácticas de consumo y segmentación social.

Palabras clave: simulacro, territorio, arte contemporáneo, segregación

\footnotetext{
Abstract

The territory is a figure that can be thought of from the simulacrum. This represents a possible threat to interpretation since it does not maintain a distance from its referent. Its geographical image may not differ from the territory or vice versa. The

1 *Universidad de la República

Tekoporá ${ }^{\circledR}$. Centro Universitario de la Región Este. Universidad de la República (C) Rodríguez. (2021)

Este es un artículo de Acceso Abierto distribuido bajo licencia Creative Commons (CC BY NC 4.0)
} 
same happens photography inherited from the mimetic tradition where its realism has produced social effects applied to advertising, science or spectacularization practices. From this perspective, Punta del Este is seen as an example of a tourist city in dispute over territory and public spaces. The displacement of communities, the exceptions to construction regulations, competition for advertising spaces, among others, are examples of the tensions that occur in this place. However, they are not always part of what is visible or narrated. The visit to the art project Bienvenidos is proposed as a trigger to think about devices that enunciate from an extra-academic place and to think about tensions linked to the territory and public spaces. Bienvenidos is a project that aims to point out and give visibility to some processes of exclusion that suggests the city as a territory in tension between public and private exchanges. The artistic project uses strategies such as staging and resources associated with advertising and the real estate market and proposes to view the territory from a contemporary point of view, as another form of subjective production related to consumer practices and social segmentation.

Keywords: simulacra, territory, contemporary art, segregation

\section{Resumo}

O território é uma figura que pode ser pensada a partir da simulação. Este último representa uma possível ameaça de interpretação na medida em que não se distancia de seu referente. Sua imagem geográfica não pode diferir do território ou vice-versa. o mesmo acontece com a prática fotográfica herdada de uma tradição mimética onde seu realismo produziu efeitos sociais aplicados nas práticas publicitárias, científicas ou de espetacularização. A partir dessa reflexão inicial, Punta del Este é vista como um exemplo de cidade turística em disputa por território e espaço público. o deslocamento de comunidades, a exceção aos regulamentos de construção, a competição por espaços publicitários, entre outros, são exemplos das tensões que ocorrem neste local. Porém, nem sempre fazem parte do que é visível ou narrado. A partir dessa constatação, a visita ao projeto artístico Bienvenidos é proposta como uma razão para pensar dispositivos que enunciam a partir de um lugar extra-acadêmico e pensar sobre as tensões vinculadas ao território e aos espaços públicos. Bienvenidos é um projeto que visa apontar e dar visibilidade a alguns processos de segregação que a cidade apresenta como um território em tensão com as trocas públicas e privadas. Use estratégias como encenação e recursos criativos associados à publicidade e ao mercado imobiliário. $O$ projeto artístico se propõe a pensar a partir do contemporâneo o território como mais uma forma de produção subjetiva relacionada às práticas de consumo e segmentação social.

Palavras-chave: simulação, território, arte contemporânea, segregação 


\section{Introducción}

Podemos pensar al territorio en clave de representación. Sólo basta imaginarlo como una cartografía, como una foto idéntica a su referente. Borges se preguntaba si tiene sentido un mapa de China tan grande como China (Sarlo, 2015).

Ese mapa, que calca punto por punto todas las prácticas, las extensiones y sus fronteras, conlleva un peligro inminente; el que no podamos distinguir la foto de su referente. Y por tanto, que no podamos distinguir las prácticas concretas de sus metáforas. Podemos fotografiar al presidente, no obstante, no podemos fotografiar la presidencia. El peligro radica en quedar envuelto en las dinámicas que nos imposibilitan entrar y salir, abstraernos y en definitiva acercarnos a la realidad como algo impensable.

Desde una mirada platónica, las herramientas de simulacro, de mímesis, nos alejan a una doble distancia de la idea. El mapa siempre será una mala copia del territorio y el territorio estará siempre a una distancia inalcanzable de la idea de nación, de democracia, de comunidad, o en este caso de territorialidad.

Por otra parte, como herencia del idealismo platónico y posteriormente cristiano, sería posible pensar al territorio como un ente homogéneo e incambiable. Es decir, en tanto idea, puro, permanente, perfecto.

No obstante, la fotografía usualmente es la instantánea de un momento y un espacio específico que no representa nunca la totalidad, que sustrae a un cuadro y propone desde la exclusión-inclusión de sus márgenes.

A su vez, en nuestros días, tenemos que pensar en la fotografía, en tanto medio digital, como un producto manipulable donde lo retocado y simulado es imperceptible. Dialoga en un mismo tiempo con lo real y su distancia mínima con la cosa representada lo hace intangible.

De la misma forma, el territorio se carga de hiperrealidad. Nuestras formas publicitarias, fotográficas, audiovisuales ya no se explican desde la representación sino que su propósito inserto en el territorio es simulacionista, camaleónico y presentador.

Esta es una historia donde las prácticas turísticas, de arquitectura urbanista, especulativas, gentrificadoras, se pegan al cuerpo y se hacen carne. Donde el territorio no puede pensarse a sí mismo porque quedó impreso en un discurso del que no sabe escapar. Y no es una ilusión, un truco, es el poder de las prácticas de hiperrealidad. Refiriéndose a la televisación como relato contemporáneo de la guerra, Baudrillard afirma "Esto es la historia de un crimen, del asesinato de la realidad. Y del exterminio de una ilusión...Lo real no desaparece en la ilusión, es la ilusión, la que desaparece en la realidad integral" (Baudrillard, 1995, p.7).

En esta realidad más real que la realidad misma, el referente desaparece como tal ya no se trata de representar, se trata de presentar, de proponer.

Desde este lugar, se propone la visita al proyecto de arte contemporáneo Bienvenidos como un insumo y disparador para pensar tensiones y prácticas asociadas al territorio y los espacios públicos. 


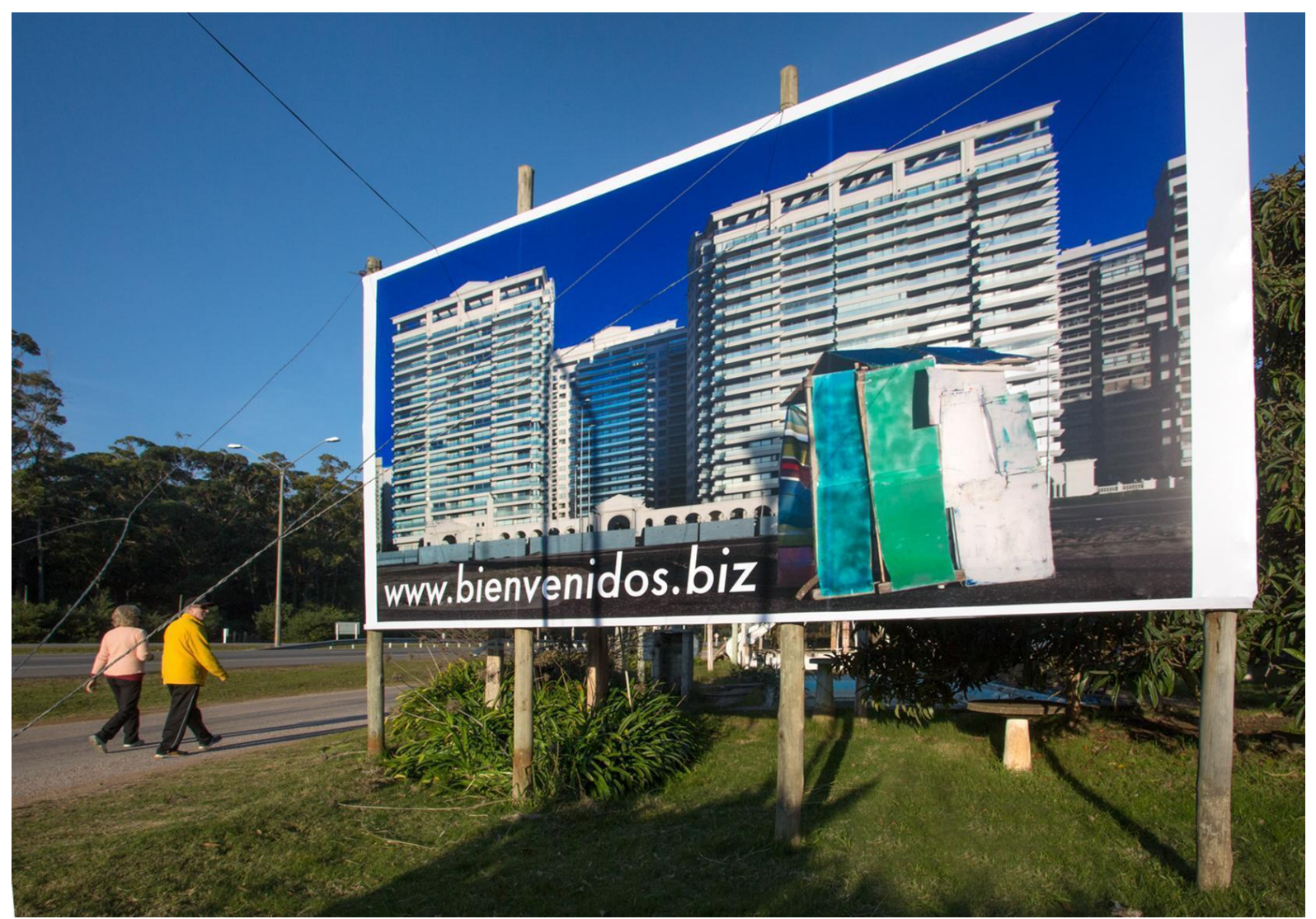

Figura 1. Registro de intervención Bienvenidos (2018) Punta Ballena, Maldonado. Fotografía del autor www. bienvenidos.biz

\section{El territorio como foto publicitaria}

Pensamos al territorio ${ }^{2}$ como un espacio de intercambio donde siempre emerge la pregunta, para qué y para quiénes, bajo qué norma y a qué precio. Son pocos los ejemplos que quedan por fuera de la pregunta. En el espacio público por herencia del concepto de polis podemos pensar que hay intersticios, grietas que se habilitan en aquello que no está completamente narrado, reglado, normalizado.

Pero el espacio público, usualmente pensado y propuesto como el espacio político por excelencia, el lugar de todos, es también un espacio en disputa. Aquel lugar que se narra como el lugar para el disfrute y el ejercicio de la ciudadanía es también un espacio donde ocurren dinámicas y tensiones en diferentes niveles.

\footnotetext{
${ }^{2}$ En esta instancia tomamos el concepto de territorio desde una mirada que confluyen muchas dinámicas al decir de Veneciano (2012): "Ya no se habla de lo urbano sino de lo territorial, que lo incluye pero lo trasciende, deja de lado la división campo-ciudad-típica del enfoque modernizador desarrollista-y estudia sus articulaciones complejas en un mundo globalizado desde distintas disciplinas sociales o formas de gestión" (p. 74).
} 
Por una parte, la capacidad de intercambio subjetivo se viene reduciendo drásticamente debido al avance de dispositivos de simulacro como la publicidad, la privatización o mediación privada de parques, plazas y playas. En el departamento de Maldonado, los proyectos de fraccionamientos, de barrios privados, clubes de campo han crecido exponencialmente en los últimos años, sumado también a este crecimiento, están las excepciones a la normativa que regula la construcción en la franja costera y que principalmente vela por la distancia mínima de la obra en relación a los cauces de agua o a la altura de las mismas. Es decir, que principalmente regula el avance físico del desarrollo inmobiliario y turístico sobre el territorio pero muchas veces no se aplica la norma aduciendo que potencialmente se generará empleo (Correo de Punta del Este, 2019). Para las comunidades que habitan en un destino turístico con acceso al mar, la playa es un lugar de encuentro de acceso democrático que en el mundo siempre está en disputa con el mercado.

Por otra parte, van en aumento los dispositivos de video-vigilancia. La Intendencia de Maldonado en el período 2015-20 instaló 1200 cámaras en los centros habitados con un costo de 20 millones de dólares (Intendencia de Maldonado, 2020). La ubicación de las cámaras no se revela a la ciudadanía como medida preventiva.

La monetización de los espacios públicos es una práctica común en las ciudades. Los espacios publicitarios en vía pública son licitados por el gobierno (Intendencia de Maldonado, 2016) a empresas internacionales.

Podemos pensar la dimensión política del territorio pero sumando a las pujas de mercado, el territorio asociado a las prácticas culturales y el uso del espacio público permea hacia la arquitectura urbana como no-lugar.

En ese sentido, me gustaría tomar dos conceptos imprescindibles para aproximarnos a este proceso cultural. En primera medida visitar el concepto de lugar.

Para el filósofo chileno Sergio Rojas (2009):

La subjetividad trama su memoria en relación al espacio que habita. A esto lo denominamos lugar. No existe un registro objetivo del lugar, sino sólo referencias, alusiones a un plano de existencia que está hecho de huellas que no cesan de articularse en el tiempo, sin pretender confundirse con la verdad. Existimos al abrigo de los lugares. (p.85)

Esta idea del lugar como un domicilio en el espacio, como un aterrizaje subjetivo, nos propone localizarnos desde la vivencia y el habitar. El lugar existe, en tanto está cargado de articulaciones subjetivas, de intercambios, de prácticas y de sentidos.

Desde esa concepción, los espacios de intercambio se perciben cada vez más cercados y disminuidos. No obstante, la ausencia de estos refugios o vínculos en el espacio público no está dada por falta de aforo. Ni necesariamente dada por reglas ni normas, sino que principalmente se articula desde la carencia de ese componente subjetivo que habilita la vivencia. Ya no pensamos el espacio como un lugar sino como tránsito. 
Ante la percepción de pérdida de comunidad en el espacio, de disminución de lugar, resuena el concepto de No-Lugar (Augé, 2000). Propone este concepto en clave de procesos arquitectónicos y urbanísticos de grandes superficies, como shoppings, aeropuertos y autopistas. Nos reconocemos a través de un ticket, un número de documento, un pass. El espacio público de ágora política cedió terreno hacia el no-lugar, hacia la mirada exteriorizada desde quien contempla desde un vehículo. Y por supuesto, contempla pero no se reconoce, no se identifica.

En este sentido, la amenaza es terminar de transformar al espacio público en un espacio de tránsito donde los individuos no sienten apego o empatía por el lugar o por alguna forma de socialización dentro del mismo. No habría una forma de vínculo que construya alguna forma de identidad, historia o narración subjetiva.

No obstante, la pregunta queda abierta ya que esta forma reciente de arquitectura y urbanismo no necesariamente explica todas las variables de nuestra vivencia en el territorio ni de nuestro arraigo comunitario y político. Son necesarias otras problematizaciones que rodeen la idea. En ese sentido, se toma el ejemplo de Bienvenidos como abordaje artístico, no lineal y extra académico,

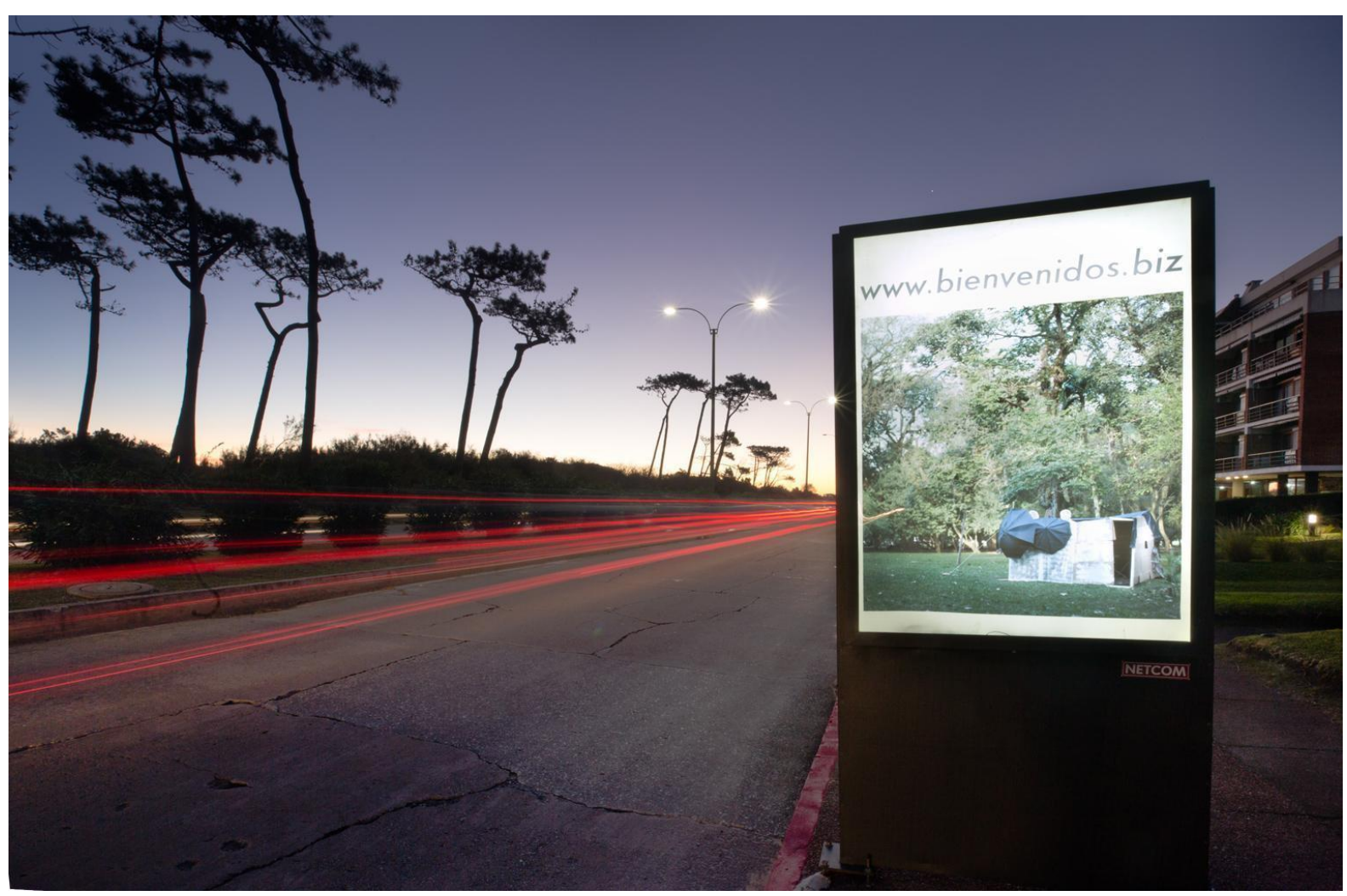

Figura 2. Registro de intervención Bienvenidos (2018) Punta del Este,

Maldonado. Fotografía del autor www. bienvenidos.biz

\section{Bienvenidos}

Bienvenidos es un proyecto artístico desarrollado entre 2014 y 2019 en el departamento de Maldonado, Uruguay y en otros destinos turísticos cómo 
Barcelona, Florianópolis, Porto Alegre y Montevideo, se nutre de estas concepciones e interrogantes para accionar poéticamente sobre el espacio público.

Utilizando el simulacro, la puesta en escena y otros recursos creativos, alude a una retórica de lo cotidiano. Insiste en la obviedad de la práctica para ganar por cansancio. Aquello que simula y propone realidad es espejo de una intención, de un discurso subyacente, de una mirada sobre la subjetividad y la ciudadanía.

Es desde ese lugar simbólico que acciona. Una actitud de observación crítica en la era de la postfotografía ${ }^{3}$ donde se propone crear con las cartas que están en juego. Donde la fotografía como un acto de captura, de revelación o de interpretación se corresponde con una mirada moderna y no con un mundo vaciado de relato y saturado de imágenes.

Bienvenidos es un proyecto artístico que tiene como objetivo señalar y dar visibilidad a algunos procesos de segregación que presenta la ciudad en tanto territorio en tensión de intercambios públicos y privados. Es un proceso sistemático de intervención donde se instalan refugios y casas precarias en espacios de interés turístico o inmobiliario. En estas relocalizaciones, se proponen estrategias que operan desde el simulacro, la ficción, la ambigüedad y la puesta en escena. Se utilizan entrevistas audiovisuales, fotografías, artículos de prensa, como insumo para la creación y posterior difusión del proceso realizado.

Opera de la siguiente manera: estructuras precarias son instaladas en el espacio público acentuando su carácter de territorio en disputa. Estas se habitan, se destruyen, se denuncian o se olvidan. Luego se genera un registro fotográfico de la intervención proponiendo una imagen intencionalmente sobre-estetizada. Imagen que articula con la mirada turística, publicitaria, del mercado, del paisaje y de la cuidada práctica fotográfica. Estos registros fotográficos, vuelven, dos años después, al circuito de la ciudad, al circuito de imágenes que en ella circula. Utilizando medios gráficos como la cartelería, el folleto, pantallas gigantes o el show room.

Propone una observación extra-académica de la reacción y el posicionamiento ético de la comunidad ante la presencia no planificada de dispositivos que ponen en cuestionamiento la propiedad, los bienes raíces, la retórica publicitaria entre otras instancias. Bienvenidos comienza en Punta del Este y se desarrolla en otras ciudades donde la especulación inmobiliaria y el turismo tienen un rol protagónico.

Su tiempo es liminal, ocurre en la fractura temporal de la fotografía y en la acción voraz de las comunidades sobre la intervención concreta. Nace del involucramiento con una problemática que se vivencia como cotidiana, propia. La violencia territorial impuesta, problematizada desde la producción y acción poética.

\footnotetext{
${ }^{3}$ Joan Fontcuberta ha denominado al homo-fotograficus como parte de este proceso en el que se hace foto de todo, todo el tiempo. Algunos hacedores de la fotografía en Europa y luego en el resto del mundo, proponen dejar de fotografiar, utilizar únicamente las imágenes que son parte del dominio público y masivo de internet, no crear más imágenes, gestionar la Fotografía 2.0. Afirman: "La que fluye por el espacio híbrido de la sociabilidad digital" (COPPEL, 2014).
} 
Se articulan insumos documentales y ficcionales propuestos desde la retórica publicitaria y mercantil. ${ }^{4}$ Nace y se desarrolla como un proyecto artístico en el territorio, que simula especularmente algunas de sus tensiones cotidianas.

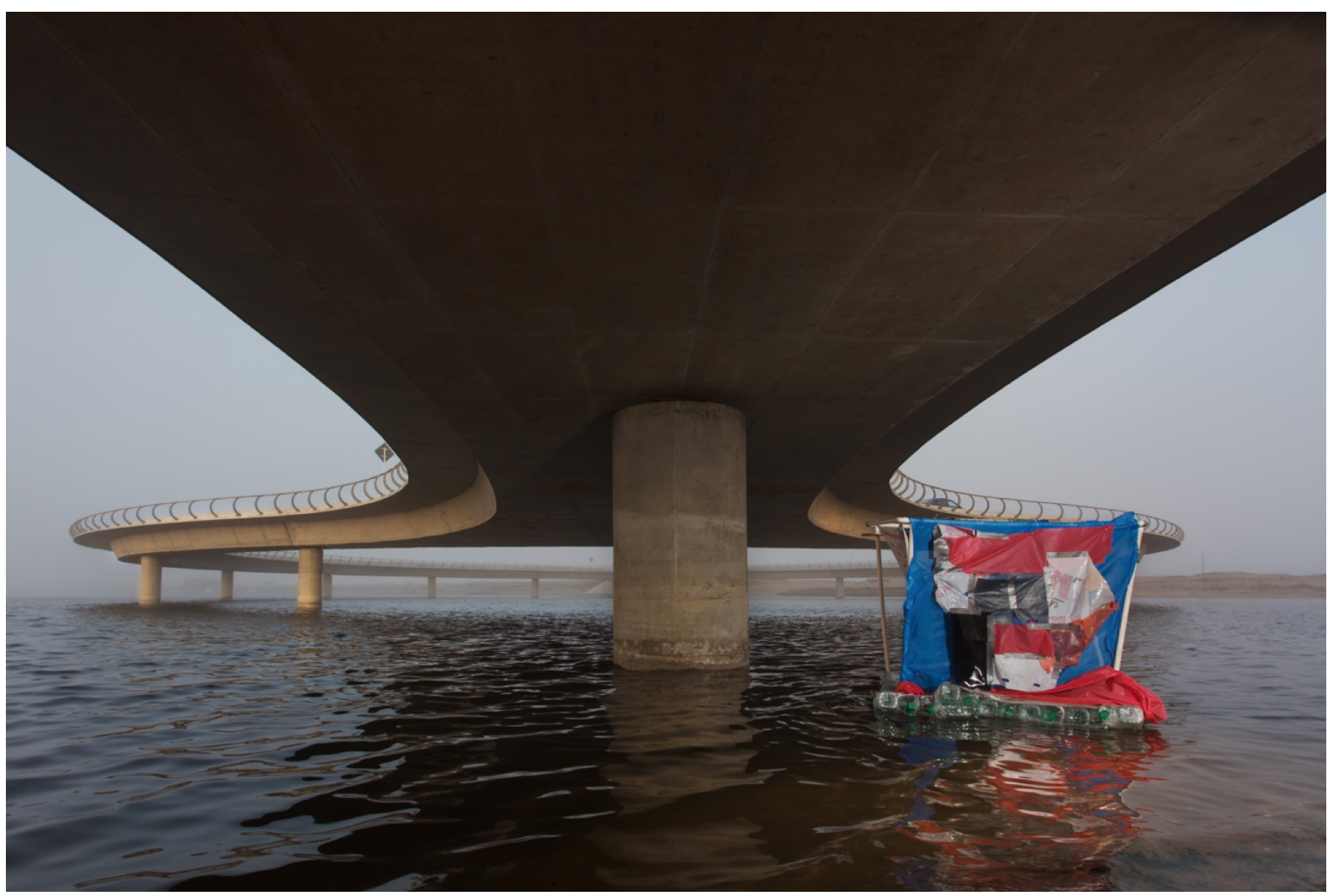

Figura 3. Sin título de la serie Virus (2016) Garzón, Maldonado. Fotografía del autor www. bienvenidos.biz

En asociación con el proyecto artístico que presentamos se pregunta la curadora Montserrat Rojas (2019):

¿Obliga Bienvenidos a detenerse a observar? ¿La obra simula ser una casa precaria y efímera la cual cobija? ¿Es posible identificarla como un espacio habitado solo por sujetos marginados? ¿O podemos ser nosotros mismos ese objeto frágil? La situación podría ser común a todas las sociedades, ya sean en vías de desarrollo o desarrolladas. La reflexión en sí no apunta a la marginalidad o la pobreza, sino más bien al significado de cómo y dónde habitamos, además de debatir si la casa es el núcleo fundamental de la sociedad, un canon tradicional que cada vez pierde fuerza, debido a las migraciones, a las nuevas estructuras de familia, el cambio climático y a la gentrificación. (Rojas, 2019, p. 4)

Las prácticas realizadas en Bienvenidos no son, ni pretenden ser un ejemplo emancipador o moral de la categoría de espacio público o del ejercicio de la ciudadanía, sino un dispositivo problematizador que aborda, desde un lugar

\footnotetext{
${ }^{4}$ Se puede ver algunas activaciones e instancias del proyecto en el sitio www.bienvenidos.biz.
} 
inesperado, el espacio público y sus disputas.

Como primera observación del territorio se alude a que algunas comunidades $^{5}$ locales son víctimas de desplazamientos territoriales ante el ejercicio de pujas de mercado y pujas gubernamentales asociadas al mercado y a la teleología de la ciudad como explotación turística.

Algunas comunidades son invisibilizadas. Si bien tienen un rol protagónico en las dinámicas socio-culturales y de mercado, no son parte de la representación simbólica de la ciudad. No son parte del imaginario o no deben salir en la foto.

En el departamento de Maldonado hay un conjunto de prácticas que accionan sobre los habitantes y que se asocian a un modelo de territorio en tanto fachada turística. Ejemplo de esto son los realojamientos de asentamientos, los desalojos, la falta de atención para los migrantes, las normativas que trazan lugares donde pueden haber malabaristas, vendedores ambulantes y esquinas que les son prohibidas, entre otras (Robaina, 2019).

Por otra parte, en el censo 2019 realizado por la ONG Techo se relevaron 12 asentamientos de densidad poblacional alta en la ciudad de Maldonado. Casi $70 \%$ de los relevados afirmaron que esa es su única vía de acceso a la vivienda. Un $45 \%$ son parte de la migración desde otro asentamiento o al crecimiento intrafamiliar 0 expansión dentro del mismo asentamiento.

En las zonas del país de mayor desarrollo poblacional y económico como Maldonado, se concentran los macro-asentamientos. En estas regiones se aceleran las dinámicas de crecimiento y concentración en relación al resto del país. No obstante, en este contexto de vivienda precaria, con mínimo o ningún acceso a servicios básicos, el $71 \%$ de las personas declararon como un aspecto positivo tener contención comunitaria. Es decir, destacaron aspectos vinculados a la organización barrial y el 53\% destacaron capacidades comunitarias, la convivencia y la tranquilidad como un valor (Gonzalez y Pasadas, 2019). Las organizaciones comunitarias responden a intereses de mejoras del hábitat y las condiciones de los servicios. Esta intención de desarrollo y empoderamiento dentro de un territorio es mucho más de lo que generalmente encontraron en sus trayectorias en las ciudades a la que pertenecen.

\footnotetext{
${ }^{5}$ Si bien el proyecto accionó en ciudades como Barcelona, Florianópolis, Porto Alegre, y Montevideo, es en Punta del Este y sus ciudades aledañas donde se generaron más cantidad de intervenciones y de acciones concretas. Principalmente porque es también el lugar en que trabajo y vivo actualmente, sumado a que la producción del proyecto logró generar más alianzas estratégicas para las intervenciones artísticas. En el mismo sentido, el proyecto fue premiado por los Fondos Concursables para la Cultura, MEC en 2018 que circunscribe su financiación al territorio nacional.
} 


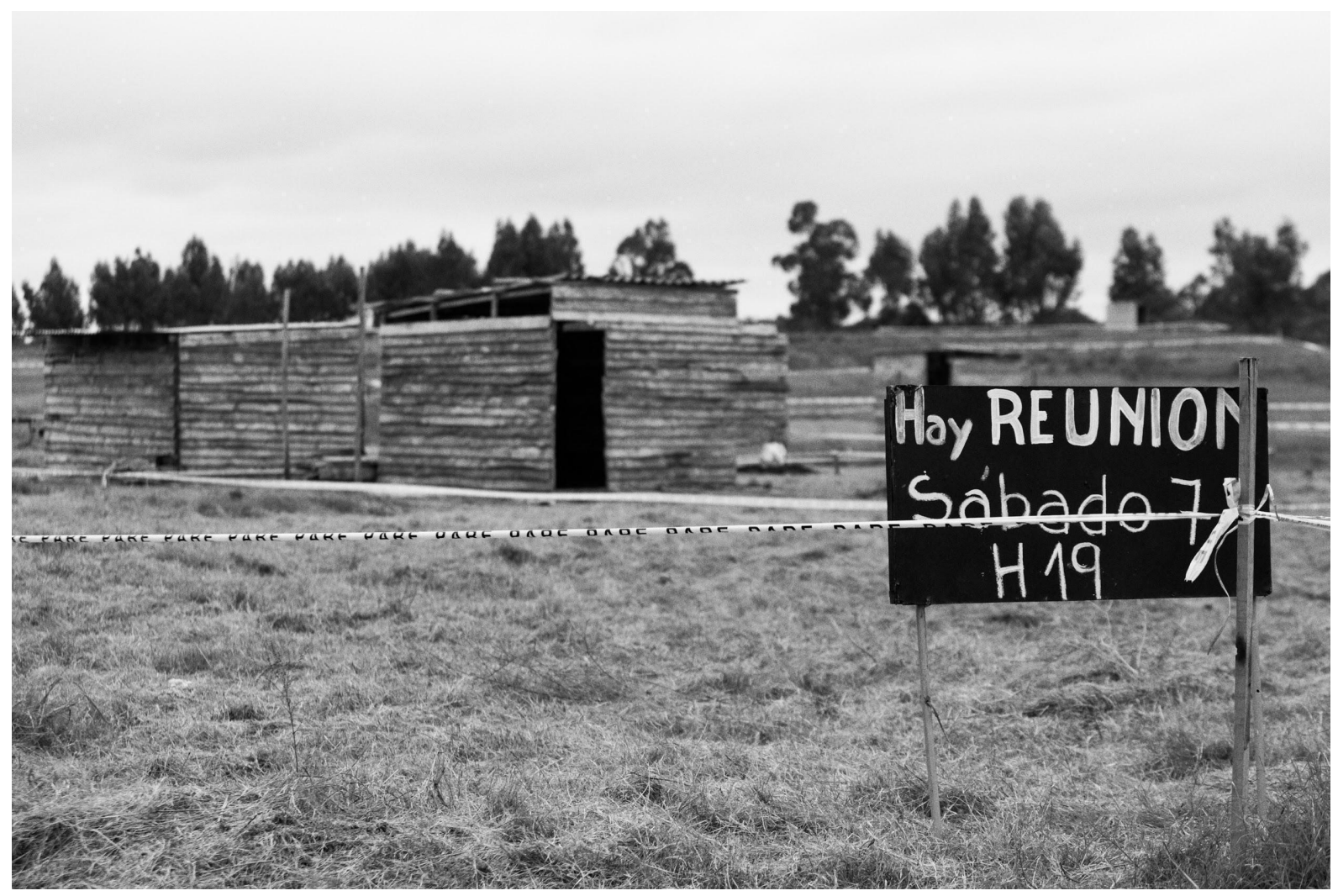

Figura 4. El Futuro en Tus Manos - Fraccionamiento Las Calas (2017)

Fotografía del autor www. bienvenidos.biz

El arraigo es una de las variables que las políticas públicas se han enfrentado y que raramente han sabido manejar en nuestra región (Rodríguez y Rudolf, 2012). El arraigo y apego se relaciona a las prácticas y sentimientos que los sujetos tienen en relación al lugar en el que habitan y explica fundamentalmente su comportamiento ante los posibles cambios.

En el contexto latinoamericano las ciudades concentraban un $10 \%$ de la población a principios del siglo XIX y pasaron a tener un $60 \%$ y $70 \%$ para finales del siglo XX (Herrera y Pecht, 1976). El fenómeno de la precarización de la vivienda, como el de la migración, no pueden ser vistos como ajenos a este proceso. 

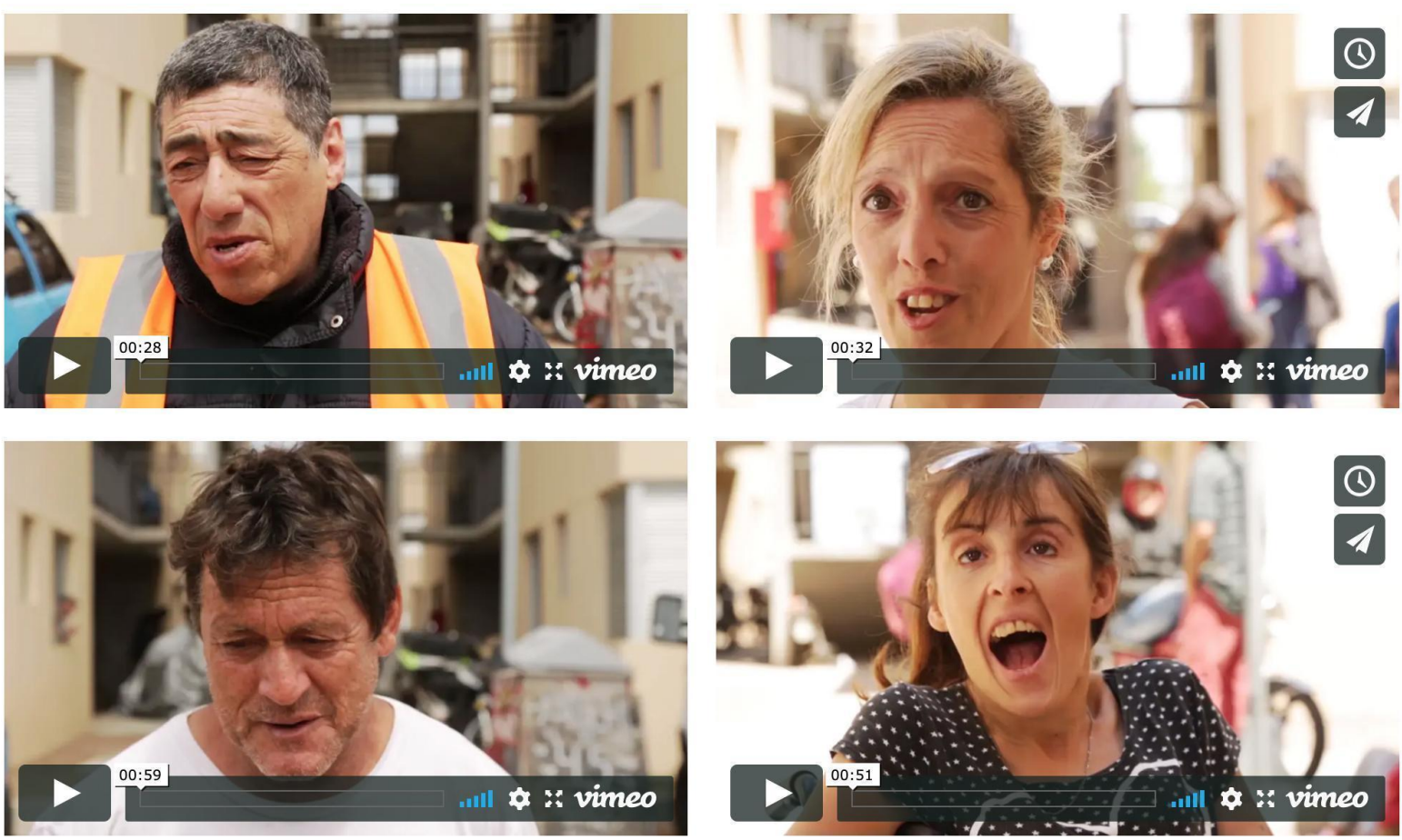

Figura 5. Conviértase en un nuevo Propietario. Testimonio de vecinos realojados en Manzana M (2018)

Fotografía del autor www. bienvenidos.biz

Entrevistas audiovisuales de vecinos realojados del asentamiento El Placer, en Punta del Este, son parte de los insumos que recoge Bienvenidos. Los entrevistados exponen sobre lo que añoran de su antigua vivienda, del entorno natural a orillas del arroyo Maldonado, de la pesca y también de los nuevos desafíos de su vivienda actual como los espacios comunes, los pasillos, los ruidos, los pleitos y los problemas constructivos de las nuevas edificaciones.

Este es un ejemplo más de las tensiones que están presentes en las dimensiones de los asentados, gobiernos locales, mercado inmobiliario y políticas sociales nacionales y locales. Se evidencia la falta de participación de los involucrados en la toma de decisiones, en los procesos de relocalización que los involucra como sujetos y como colectivo; más allá de que los relevamientos nos muestran que ese es un factor fundamental para construir relación con su entorno. En ese sentido se denota que no hay una estrategia de reconocimiento como actores locales, de prácticas descentralizadoras ni de desarrollo local. ${ }^{6}$

A modo de ejemplo, otro insumo fotográfico que recoge el proyecto es la intervención realizada por vecinos del fraccionamientos Las Calas (Maldonado Noticias, 2017) en Maldonado. Estos fueron estafados por la parte propietaria del fraccionamiento. Al no hacerse efectiva la entrega de los terrenos comprados, los nuevos propietarios decidieron instalarse extrajudicialmente en construcciones precarias, similares a las que encontramos en los asentamientos de la periferia

\footnotetext{
${ }^{6}$ Para Arocena (2013) son claves para definir el desarrollo local y la participación de los actores locales, la producción de riqueza local, el sentido de pertenencia y aspectos identitarios de la población para producir y gestionar los bienes y servicios del territorio (p.6).
} 
urbana. Esta acción de ocupar la tierra para convertirla en cartelería, en refugio tiene un carácter simbólico que se relaciona con el arraigo pero también con una práctica de simulacro que toma el proyecto Bienvenidos como insumo propio. Se habita un lugar que se defiende como propio en un tiempo de espera y tránsito en el marco de un proceso judicial.

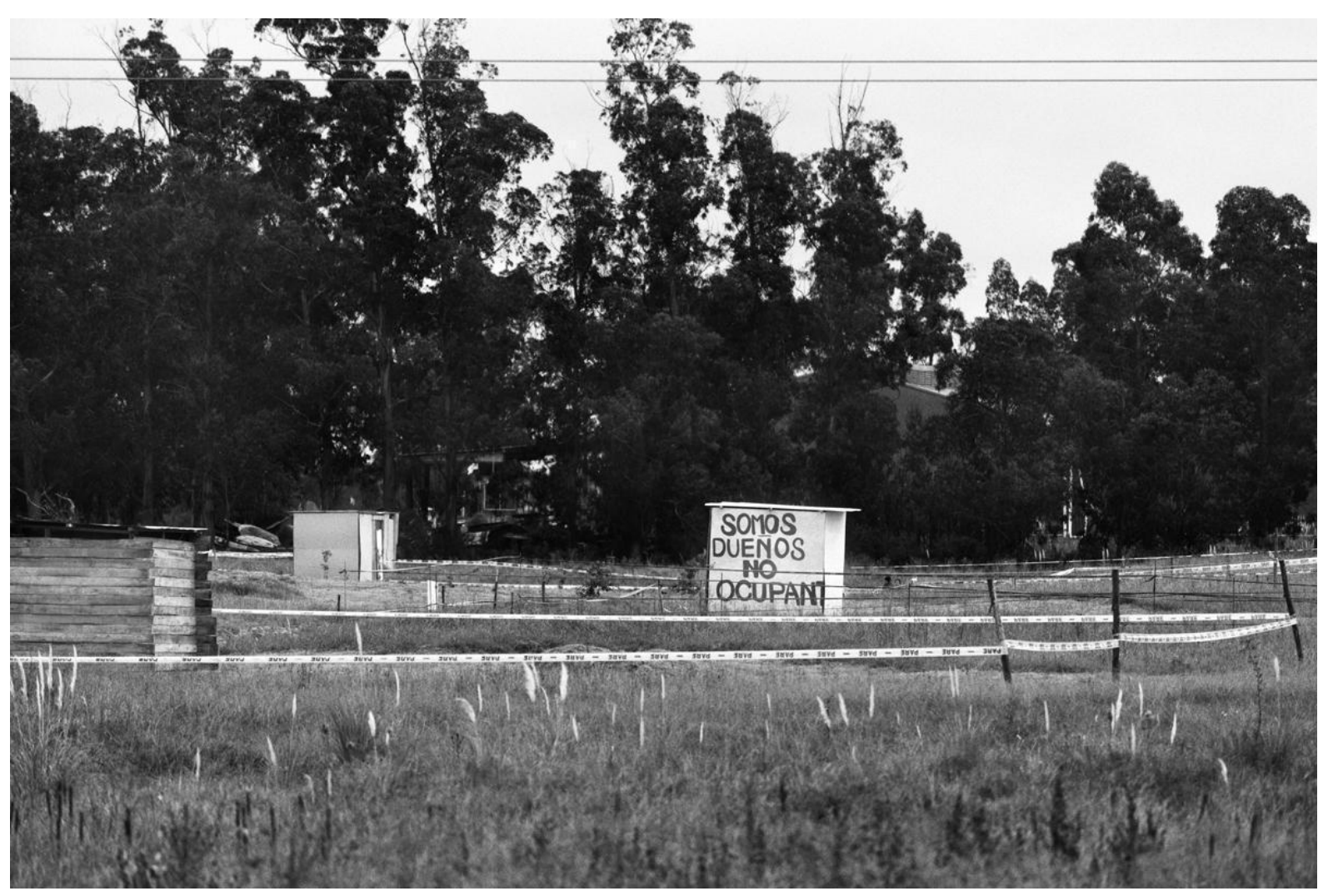

Figura 6. El Futuro en Tus Manos - Fraccionamiento Las Calas (2017)

Fotografía del autor www. bienvenidos.biz

\section{Recrear el espacio público}

En estos intersticios de lo no completamente narrado, y donde quedan no dichos, fuera de lo reglado ${ }^{7}$ en este campo de permanente disputa, se presenta una oportunidad para las prácticas artísticas contemporáneas. Podría ser ahí un lugar donde aún es posible simbolizar y enunciar.

En este sentido es importante situarnos y enmarcar conceptualmente la intención de arte y de contemporaneidad. Si bien ocuparía otro artículo analizar estos conceptos, podemos convenir en que el arte es hijo de un mundo concebido como moderno e integrado en un relato. Un relato emancipatorio, iluminista, europeo, civilizado y colonialista. Que en su devenir histórico confluyen la

\footnotetext{
${ }^{7}$ Sobre todo, refiriéndonos a los usos y prácticas no regladas del espacio público, que hacen modos de vida fuera de lo originalmente pensado o planeado, que articulan prácticas colectivas o en red, que no pueden preverse dentro de una práctica disciplinada en el espacio público.
} 
intención de representación y belleza; la función poiética o acto creativo y la metáfora como la invitada infaltable que las disciplinas o prácticas invocan. No obstante, esa metáfora, también ha devenido en simulacro, en tanto estrategia simbólica y representativa, y los territorios específicos ya no lo son tanto: "la historia contemporánea del arte es una combinación paradójica de conductas dedicadas a afianzar la independencia de un campo propio y otras empecinadas en abatir los límites que lo separan" (García Canclini, 2010, p.19).

Las vanguardias artísticas del siglo XX se han encargado de cuestionar aspectos vinculados al gusto, a la representación mimética y a la belleza como valor intrínseco. Una forma deconstructiva del orden establecido en el gran relato del Arte estaba instalada: he aquí la semilla de nuestra contemporaneidad.

Para Andrea Giunta (2014) el arte moderno, inaugurado a finales del siglo XIX por pintores naturalistas e impresionistas, funciona desde la correspondencia de un relato progresivo entre artistas. Es decir, opera desde la transformación evolutiva del relato de la obra. El punto de llegada fue la abstracción y más aún el arte concreto donde primero, se rompe con la idea de representación de un mundo exterior a la obra y en segundo lugar emerge un nuevo mundo a través del objeto.

Este último es el punto de inflexión para el nacimiento del arte contemporáneo donde lo primero que se rompe es la idea de continuidad en el relato entre movimientos y obras. Para el relato histórico del arte contemporáneo es la postguerra un punto de partida que tiene sus primeros ecos en los años 50 tanto en Europa como en Latinoamérica y que sin duda se consolida como discurso global a finales de los 80 (post guerra fría) con la eclosión del bienalismo. De esta forma "el mundo del arte se volvió simultáneo y dejó de ser evolutivo" (Giunta, 2014, p.14).

El aterrizaje inmediato de la palabra contemporáneo, donde cada uno habita en su tiempo, nos plantea la dificultad de enmarcar un territorio en concreto. No obstante, para explicar lo contemporáneo en el arte, su definición etimológica no nos acerca demasiado.

En contraposición, podríamos postular que existe en nuestra condición contemporánea, referida al contexto occidental de los últimos 30 años, una característica del no-relato como aspecto central. Y sobre todo una pretensión de pensarse en términos globales, dejando a los proyectos emancipatorios nacionales como un discurso demodé, abandonando la pertenencia al proyecto Moderno. ${ }^{8}$

El arte contemporáneo puede ser visto como un arte que está involucrado en la reconsideración o en el abandono del proyecto moderno. Podría decirse que vivimos una época de indecisión, de demora, un tiempo aburrido (Groys, 2014). En ese sentido, lo aburrido o el aburrimiento como plantearía Heidegger es una antesala de la percepción del presente.

También podemos señalar a la contemporaneidad en términos de actitud y no de actualidad. Actitud también extemporánea, crítica, que mira fijo a su tiempo desde afuera que opera de manera intempestiva, fuera de su tiempo, como plantea Agamben (2008):

\footnotetext{
${ }^{8}$ Más allá que las instituciones que nos rigen políticamente aún hoy estén constituidas en ese relato.
} 
El contemporáneo es aquel que percibe la oscuridad de su tiempo como algo que le corresponde y no deja de interpelarlo, algo que, más que otra luz se dirige directa y especialmente a él. Contemporáneo es aquel que recibe en pleno rostro el haz de tinieblas que proviene de su tiempo. (Agamben, 2008, p.3)

Y en este caso, si pensamos la actitud contemporánea en el arte desde el espacio público encontramos criterios que desarman las lógicas institucionales y de legitimación. En ese sentido para Delgado (2013) el "Artivismo" es una tendencia de simbolización dentro del espacio público que apela a

la aplicación de criterios de participación e involucramiento que desmientan la distancia entre creador y creación, o entre público y acción; empleo de estrategias de guerrilla simbólica; el papel asignado al humor, al absurdo y a la ironía; la renuncia a toda centralidad, a las definiciones y a los encapsulamientos; la concepción del artista como activista, es decir como generador de acontecimientos. (Delgado, 2013, p.70)

Es posible, si se quiere pensar al arte como un proyecto que mantenga conexión política-social y al mismo tiempo sea pretencioso en su vocación de contemporaneidad, habilitar al espacio público como fuente de acceso.

Y no se trata de pensar románticamente a la calle, ya que sabemos que el tour artístico comercial también se alimenta de estas prácticas. Como por ejemplo: Surrounded Islands por Christo y Jeanne-Claude que se realizó en 1983 interviniendo once islas en Miami y poniendo en marcha a más de 500 operarios; o los stencils de Bansky donde se han pagado más de 1,2 millones de dólares por una copia en una subasta. Incluso pensando en que esa fagocitación simbólica puede ser violenta como la obra de Santiago Sierra donde un perro callejero de un barrio periférico de Managua muere atado en una muestra que el artista ofrece en una galería de Nicaragua.

Esa ambigüedad histórica y conceptual del arte y de la contemporaneidad propone una tensión irresuelta. Cuando una opera con plenitud la otra se desvanece. Es decir que lo que sucede en primer lugar es un debilitamiento de las categorías modernas pensadas desde una dimensión contemporánea. Y esto lo podemos aplicar, al arte, a la política y al espacio público.

Si pensamos en estética usualmente relacionamos el término a la filosofía estética en tanto una rama de pensamiento que se ocupa de lo bello o lo sublime y desde un punto de vista kantiano, del gusto o el disgusto.

Generalmente estos conceptos asociados justamente al valor estético también son heredados de una concepción idealista donde el acceso a estas máximas nos es generalmente vedado. Es decir, corresponde más a una búsqueda de un ideal inalcanzable.

Más adelante, esta concepción es actualizada en el estudio del fenómeno kantiano hacia una experiencia estética. Por ende, ahora también provista de sensibilidad y cuerpo de un sujeto concreto que es capaz de percibir.

Es decir, paradójicamente los valores estéticos que pertenecían al mundo de 
las ideas son aterrizados a través de la percepción en un sujeto. Pasan a ser parte de la emoción, de la experiencia sensible y perceptiva.

Antes de relacionarlos con el arte o con la técnica, es la estética una forma de relacionarnos con el mundo y principalmente de experimentarlo. Es esta experiencia la que habilita al goce, aquel que suspende el sentido, donde el lenguaje ya no opera y emerge la fascinación.

Si lo asociamos al quehacer artístico la experiencia estética se brinda al público. Un público que entiende, que se circunscribe socialmente a un gusto, una educación concreta, una actitud estética.

No obstante, el concepto de estética asociado a un consumo contemplativo se diluye cuando lo pensamos desde la sociedad contemporánea. Para Groys (2014) como para los fotógrafos de la post-fotografía, "hoy en día, hay más gente interesada en producir imágenes que en mirarlas" (Groys, 2014, p.14).

Por tanto, nuestra experiencia en el arte contemporáneo ya no puede ser analizada en términos estéticos sino poéticos o poiéticos, más allá que nos consideremos ajenos a la creación artística. Propone un cambio de perspectiva donde el productor, en tanto creador, no sólo de obras, sino de su propia imagen pública, en sus perfiles y avatares, es el eje del análisis y no el público, en tanto consumidor de arte o portador de la experiencia estética. Esto propone una forma de participación, donde "así, la dimensión política del arte tiene menos que ver con el impacto en el espectador y más con las decisiones que conducen, en primer lugar, a su emergencia" (Groys, 2014, p.15). También desde una actualización de la estética, la tríada artista-obra-público tiene que repensarse.

Por esto, Bienvenidos propone ubicar al público en el lugar de consumidor, un lugar ambiguo. Donde uno no participa por convicción, sino que las cosas le son dadas o simuladas. Donde tampoco está claro qué es lo que se vende o cuales son las decisiones que uno podría tomar como participante.

\section{Conclusiones}

En la órbita de las representaciones podemos pensar al territorio como espacio mental. Para la psicología la mente no coincide biológicamente con el cerebro. No corresponde el espacio mental con la asignación y coincidencia de un mapa cerebral. No podemos asignar nuestra psiquis a una neurona específica o controlarla desde ahí. Nuestra mente funciona como un espacio simbólico cargado de nuestra experiencia desde el momento que nacemos en adelante. Nuestros deseos y nuestras faltas, nuestras fijaciones y proyecciones, constituyen parte de este mapa cargado de símbolos y de sentidos que no podemos completamente biologizar.

El territorio como extensión de nuestra subjetividad no responde de manera diferente. No es un mero espectador en nuestra experiencia física, ni puede referirse únicamente a lo material. Habita autopoieticamente en una matriz virtual, como los dispositivos electrónicos y en otras tantas, como las instituciones, la casa, la familia o la pareja. Así como el cuerpo expone sus extensiones, el territorio también se vivencia desde nuevas prácticas ciudadanas. 
El espacio público tal cual lo conocemos, o al menos tal cual lo enunciamos solemnemente, como aquel espacio político por excelencia, ya no tiene un rol excepcional ni excluyente. Es parte de nuestra performatividad política, de nuestra convivencia comunitaria como tantos otros. Incluso bastante menos que otros. Esta convivencia dentro de una matriz individualista facilita el abandono subjetivo del espacio público y por consiguiente deja terreno fértil para otras instancias de uso, de explotación o de intercambio.

El peso político del sujeto en el espacio público pierde fuerza ante la caída de su lugar simbólico, ante la transformación de lugares en no-lugares. Las tensiones y pujas en tanto disputas políticas se hacen cada vez menos visibles ya que nuestro ejercicio social y político está diseminado.

La idea de territorio forma parte de nuestro espacio mental, incorporado a nuestras prácticas. Queda planteado como tatuaje, como cicatriz y como mapa.

Una sociedad espectacularizada, regida por lógicas simulacionistas y de mercado no puede trazar su territorio como lo pensábamos en la modernidad. Sus recorridos, sus trazos y sus mapeos responden a prácticas segmentadoras, dispersas pero al mismo tiempo cercadas en sus propias dinámicas.

Entonces, cuando la ciudad, y sobre todo las metrópolis, pierden localía y ganan en tanto espacio vacío, en tanto mercancía, el espacio público no resuena en su sentido político. No evoca su antiguo discurso emancipador donde el espacio público se vuelve territorio de intercambio, de esa práctica sólo queda la huella. Las manifestaciones políticas pierden efecto o se perciben como ineficientes o atemporales y "el uso masivo de la ciudad para la teatralización política se reduce; las medidas económicas y los pedidos de colaboración al pueblo se anuncian por televisión" (García Canclini,1990, p.257).

En este contexto primero televisado, luego interconectado, y ahora incorporado como extensión al cuerpo, es el espacio público el que ha devenido en simulación. No únicamente atendiendo a su inoperancia en un sentido simbólico y político, es decir porque no opera como lugar de intercambio sino como una práctica altamente direccional y predeterminada. Sino también, porque el espacio público es simulado operando más allá de su territorialidad. Su diseminación es paradójicamente un síntoma de lo cercado, de su especificidad, de sus límites. La simulación del espacio público es una forma de subjetividad que propone un nuevo ejercicio de la ciudadanía. No podemos pensarla como una representación de las viejas categorías porque eso nos pone en el lugar de la añoranza de algo que no es y por sobre todo porque no remite a esa lógica simbólica.

Somos espectadores segmentados de la ciudad y de sus espacios. Nuestra identidad está referida a nuestra segmentación territorial, a nuestro barrio, a nuestra escuela, a nuestro espectro de consumo geo-localizado y a nuestros vínculos empáticos que se construyen y mapean en ese tránsito.

En territorios de puja de mercado y turismo, incluso en sus espacios públicos, el uso está regulado únicamente para fines turísticos, recreacionales y de consumo. En Punta del Este se ha impedido repetidas veces, mediante intervención policial y gubernamental el ejercicio de manifestaciones políticas y el ingreso a la 
ciudad a personas con intenciones de manifestarse (La Red21, 2003).

Para Néstor Casanova (2020), "ya no se habita, como antes, en Montevideo o Buenos Aires, sino que se vive en Pocitos, Punta Carretas, Palermo o Recoleta". Se trata de aislarse en un espacio propio, como sinónimo de un estilo de vida, de prácticas de consumo. El simulacro del espacio público refleja una nueva forma de habitar la ciudad. Nuestras prácticas son un reflejo especular de nuestra posición socio-territorial. Y parte de estas, son las formas de intercambio a través de los logaritmos a los que nos exponemos y de los que somos parte.

El peligro ya no es que no podamos diferenciar la foto de su referente o que no podamos distinguir el mapa del territorio. Sin duda ambos conceptos están irremediablemente sujetos el uno al otro. Vale dudar cuando el lugar homogéneo y empático siempre se visualiza como una fachada recién pintada.

\section{Referencias}

Agamben, G. (2008). ¿Qué es lo contemporáneo? Seminario en Facultad de Artes y Diseño de Venecia, Italia.

Arocena, J. (2013). El desarrollo local, una aproximación conceptual. +E: Revista De Extensión Universitaria, 3 (3), pp. 6-13. Recuperado de: https://doi.org/10.14409/extension.v1i3.466

Augé, M. (2000). No lugares. Espacios del anonimato. Madrid, España: Editorial Gedisa.

Baudrillard, J. (1995. El crimen perfecto. España: Anagrama.

Casanova, N.(2020). La segregación socioterritorial urbana. Vadenuevo.com,uy Recuperado de:

https://new.vadenuevo.com.uy/sociedad/la-segregacion-socioterritorial-ur bana/

Coppel, E. (2014, Junio 5). Ahora se llama «Postfotografía» Diario EL Mundo. Recuperado de: http://www.elmundo.es/cultura/2014/06/05/538f5071268e3eb25a8b45 8b.html

Correo de Punta del Este (2019, septiembre 24). Preocupa que se dilate inicio de obras de construcción aprobadas con excepciones. Recuperado de: http://correopuntadeleste.com/preocupa-que-se-dilate-inicio-de-obras-deconstruccion-aprobadas-con-excepciones/

Delgado, M. (2013). Artivismo y pospolítica. Sobre la estetización de las luchas sociales en contextos urbanos. QuAderns-e. Institu Catalá d'Antropologia, 18 (2), pp. 68-80. Recuperado de https://www.raco.cat/index.php/QuadernseICA/article/view/274290 
García Canclini, N.(1990). Culturas Hibridas. Estrategias para entrar y salir de la modernidad. México: Grijalbo Editorial.

García Canclini, N. (2010). La Sociedad Sin Relato. Antropología y Estética de la Inminencia. Buenos Aires, Argentina: Katz Editores.

Giunta, A. (2014). ¿Cuándo empieza el arte contemporáneo? Ciudad Autónoma de Buenos Aires, Argentina: Fundación arteBA

Gonzalez, B. y Pasadas, L. (2019). Relevamiento Nacional de Asentamientos. Techo. Uruguay, 2019. Recuperado de: www.techo.org

Groys, B. (2014). Volverse público: las transformaciones del arte en el ágora contemporánea. Ciudad Autónoma de Buenos Aires, Argentina: Caja Negra.

Herrera, L. y Pecht, W. (1976). Crecimiento Urbano en América Latina. Santiago de Chile, Chile: Centro Latinoamericano de Demografía BID.

Intendencia de Maldonado. (2016, diciembre 12). Cinco interesados en la explotación de la publicidad en espacios públicos del departamento. Web institucional. Recuperado de: http://www.maldonado.gub.uy/?n=27297

Intendencia de Maldonado. (2020, diciembre 10). Centro de Video Vigilancia. Web Institucional. Recuperado de:

http://www.maldonado.gub.uy/?p=a02ffd91ece5e7efeb46db8f10a74059

LaRed21. (2003, febrero 6). Antía prohibió al PIT-CNT homenaje a primera marcha a Punta del Este. Recuperado de:

https://www.lr21.com.uy/politica/105926-antia-prohibio-al-pit-cnt-home naje-a-primera-marcha-a-punta-del-este

Maldonado Noticias. (2017, agosto 9). Fraccionamiento Las Calas fue adquirido en remate judicial por el propio hipotecante. Recuperado de: https://maldonadonoticias.com/beta/actualidad/10059-fraccionamiento-l as-calas-fue-adquirido-en-remate-judicial-por-el-propio-hipotecante.html

Robaina, M. (2019, septiembre 6). En el Aire. Brecha. Recuperado de: https://brecha.com.uy/en-el-aire-2/

Rodríguez, A. y Rudolf, S.(2012). Construcción del ambiente residencial. Montevideo,Uruguay: Departamento de Publicaciones, Udelar.

Rojas, M. (2019). Bienvenidos - Proyecto Moebius. Centro de Exposiciones Subte. Intendencia de Montevideo. Recuperado de: 
https://subte.montevideo.gub.uy/exposiciones/pasadas/2020/ignacio-rod riguez-srabonian-bienvenidos-proyecto-moebius

Rojas, S. (2009). Las obras y sus relatos II. Chile: Ediciones del Departamento de Artes Visuales. Facultad de Artes de la Universidad de Chile.

Sarlo, B. (2015). Borges, un escritor en las orillas. Buenos Aires, Argentina: Siglo Veintiuno editora.

Veneziano, A. (2012). Los dos paradigmas de la descentralización. Revista Pampa, 8 ISSN 2314-0208. 